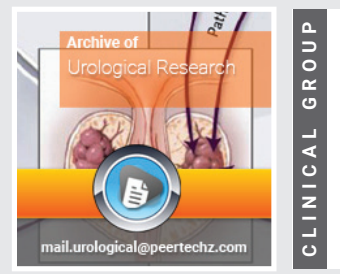

\section{New Technique for the} Treatment of Anterior Hypospadias Doubles-Y Glanuloplasty prospective

\section{Evaluation and A Systematic}

\section{Review}

\section{Lahfaoui* and $\mathrm{H}$ Benhaddou}

Department of Pediatric Urovisceral Surgery, Faculty of Medicine and Pharmacy, Mohamed-Premier University, CHU Mohamed VI, Oujda, Morocco
Received: 25 April , 2020

Accepted: 05 May, 2020

Published: 06 May, 2020

*Corresponding author: M Lahfaoui, Department of Pediatric Urovisceral Surgery, Faculty of Medicine and Pharmacy, Mohamed-Premier University, $\mathrm{CHU}$ Mohamed VI, Oujda, Morocco,

E-mail:mohammedlahfaoui@gmail.com

Keywords: Anterior hypospadias; Double $Y$ glanduloplasty; Child

https://www.peertechz.com

Check for updates

\begin{abstract}
Introduction: Hypospadias is the ectopic closure of the urethral meatus at the ventral surface of the penis. The diversity of techniques proposed to treat hypospadias has caused a great debate among urologists about the effectiveness of these techniques. The objective of our study is to develop the double $Y$ glanduloplasty technique, expose and compare the results of this technique to improve the management of anterior hypospadias.
\end{abstract}

Material and method: Our prospective study is conducted on 18 patients treated for anterior hypospadias with the double $Y$ glanduloplasty technique between January 1, 2017 and June 30, 2019 in the pediatric visceral and urogenital surgery department at Mohamed VI- Oujda University Hospital.

Results and discussion: Previous hypospadias was generally discovered by the mother in $45 \%$. The average age of the PEC was 4.32 years. The anatomical varieties operated by the DYG technique were balanic and balanopruputial with equal percentages, $50 \%$ each. The most common malformation was incomplete foreskin (45\%), followed by penis curvature (33\%) and cryptorchidism (16\%). $78 \%$ of the cases operated on were uncircumcised. The after-effects of the operation: were simple. The complication rate was $16 \%$ ( 2 cases of fistula, 1 case of partial meatus stenosis). $83 \%$ of parents were satisfied with the results.

Conclusion: Comparison of double Y glanduloplasty with other techniques used in anterior hypospadias shows that complications are much less frequent with DYG, with satisfactory aesthetic and functional results. So we strongly recommend the use of this technique in glandular hypospadias with a mobile meatus and without deep curvature of the penis.

\section{Introduction}

Etymologically the term "hypospadias" is derived from the Greek "hypo" which means below and "spade" meaning crack or slit. Hypospadias (Figure 1) [1], is a congenital malformation due to the absence of fusion of the urethral floor to the tip of the penis, resulting in incomplete development of the penile urethra and early termination of the urethra to the anterior surface of the penis. Depending on the type of hypospadism, this abnormality may be accompanied by anterior curvature of the penis, stenosis of the ectopic mechanism, malformation of the foreskin called a sapper's apron, micropenis, cryptorchidism, or other male sexual development anomalies. It is one of the most frequent genital anomalies and its prevalence has been constantly increasing in recent decades. The classification of hypospadias is based on the location of the urethral meatus. The least severe previous forms are by far the most frequent. The consequences of an unoperated hypospadias can be urinary; genital or psychological and behavioural. The perfect correction of hypospadias remains one of the paediatrician's 


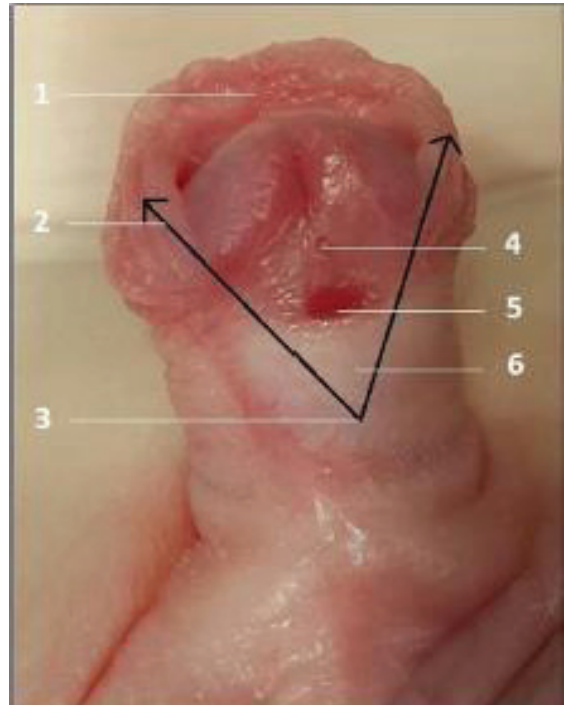

Figure 1: Surgical anatomy of the hypospad [1]

1. prepuce in "sapper apron";

2. mucocutaneous junction;

3. division of the spongy body

4. urethral gutter;

5. ectopic abutment of the urethral meatus;

Hypoplastic urethra (absence of cancellous tissue)

largest chalenges. The multitude of interventions described (more than 250) testifies both to the ingenuity of their authors and to the lack of certainty about their outcome. The aim of these surgeries is to obtain a correct cosmetic result and a good functional result in the long term, both in terms of urination and sexual function, without the malformation leaving too many traces on the psychological level.

Our study focused on 18 cases of previous hypospadias managed between January 1, 2017 and June 30, 2019 in the pediatric visceral and urogenital surgery department at Mohamed VI University Hospital in Oujda, using the double Y glanduloplasty technique, and aims to develop this technique and evaluate these results.

\section{Materials and Method}

\section{I- Type of study}

This work is a prospective study of 18 cases of anterior hypospadias managed in the pediatric visceral and urogenital surgery department at Mohamed VI University Hospital in Oujda. Between 1 January 2017 and 30 June 2019.

\section{II - Objectives}

The objective of this study is:

Focus on the double Y glanduloplasty technique.

$>$ Explain the results of this technique in the management of prior hypospadias in our service.

$>\quad$ Compare our results with the author's series of this technique on the one hand, and with the other techniques described in the literature on the other.

\section{III - Inclusion criteria}

$>\quad$ Patients with previous hypospadias

$>\quad$ The Indications of DYG technique:

- Anterior hypospadias

- With a mobile meatus

- Without deep chordate

$>\quad$ The patients are all new cases that have never been treated.

\section{IV - Exclusion criteria}

Inoperable records have been eliminated.

Patients already operated on by other techniques.

Patients with moderate or posterior hypospadias were eliminated.

\section{V- Data collection}

Several factors were studied, and the analysis of the files was carried out according to a farm return taking into consideration the following elements:

Age of discovery Age of 1st consultation Circumstance of discovery; Origin ATCD; Clinical examination; Surgical technique; Duration of the procedure; Anesthesia; Urinary drainage; Dressing; Surgical follow-up; Duration of hospitalization; Antibiotic therapy treatment; Evolution and complications; Final result; Retreat.

\section{Result}

In our study the average age of discovery of hypospadias was 7 months with a range of D1of life - 13 years. While the average time between the discovery of hypospadias and the 1st consultation at the University Hospital and 22 months. The average age of the PEC was 4.32 years.

In our series, anterior hypospadias was generally discovered by the mother by finding an abnormal position of the urinary meatus or an anomaly of the jet in $45 \%$.

$2^{\text {nd }}$ place; during circumcision: $33 \%$. Systematic discovery in the birth room concerned only $22 \%$ of patients. 5 cases with specific ATCDs or $27 \%$, including:

1 case of hemophilia "A" operated on under factor VIII prophylaxis.

1 case already operated for removal of vegetation.

1 case already operated for left testicular ectopy.

1 cases of prematurity hospitalized in neonatology.

$>1$ family case of hypospadias was found in our series, a rate of $5 \%$. 
The anatomical varieties operated by the DYG technique were balanic and balanopruputial with equal percentages, $50 \%$ each. 4 types of associated malformations have been described in our patients. The most frequent malformation was incomplete foreskin in 8 cases (45\%); 6 patients followed by penis curvature (33\%), cryptorchidism in 3 children (16\%) and only one patient with a micropenis $1(5 \%)$.

$78 \%$ of the cases operated on were uncircumcised.

General anesthesia was performed in 10 patients or $55 \%$ of cases. In addition, sedation+ spinal anaesthesia was performed in 8 patients or $44 \%$ of cases.

Surgical technique (DYG): (Figure $2 \mathrm{~F}$ )

> Under general anaesthesia or spine anaesthesia plus sedation.

$>$ Verification of urethral plate mobility.

$>$ Traction on the glans with a 5/0 nylon.

$>$ An inverted $\mathrm{Y}$-shaped incision is made on the glans. The center of the inverted $\mathrm{Y}$ is just above the distal crest of the meatus. Each axis of the inverted $\mathrm{Y}$ is $0.5 \mathrm{~cm}$ long and the angle between the axes is $60^{\circ}$.

$>$ The incision is deepened and the flaps are mobilized to allow more mobility of the meatus.

$>$ The meatus is attached to the tip of the glans with a $6 / 0$ vicryl.

$>$ In case of a punctiform or narrow meatus, it can be incised to make it wide enough to receive a hinge probe 10 or larger depending on the patient's age and penis size.

A bladder catheter is performed with a hinged bladder catheter 10.

$>\mathrm{A} 2^{\text {nd }} \mathrm{Y}$-shaped incision is made near the neo-meat, the use of sharp scissors and traction helps to avoid injuries to the very thin urethra under the skin.

The traction is applied to the glandular wings and the incision is deepened with pointed scissors from the coronary groove.

$>$ The glandular wings are mobilized out of the urethra and open like an open book. This allows the glandular wings to be wrapped around the urethra without tension.

$>$ Dissection around the meatus to release the lateral attachments of the urethra.

$>$ The upper edges of the 2 glandular wings are fixed to the edges of the urethral meatus using of 3 stitches with vicryl $6 / 0$ or $7 / 0$.

$>$ The medial edges of the glandular wings are sutured on the median line using Vicryl 7/0.

\section{Surgical circumcision.}

$>$ Final appearance (Figure $2 \mathrm{~F}$ ).

$>$ A greasy dressing has been applied to all patients and is applied to the wound. A tape attaches the gauze pad, catheter and penis to the lower abdominal wall (Figure 3).

The transurethral catheter is left for 48 hours. The average duration of the intervention is: 45min. Urinary drainage: All patients were drained by a urinary catheter, with an average duration of 48 hours. Antibiotic therapy: antibiotic prophylaxis is systematically used. Duration of hospitalization: the average
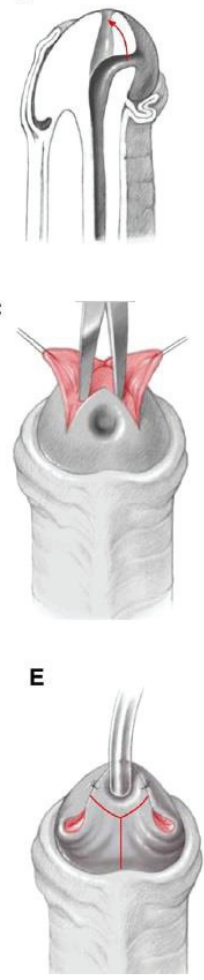

B

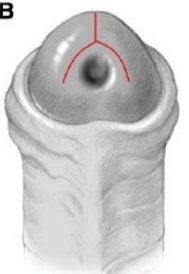

D
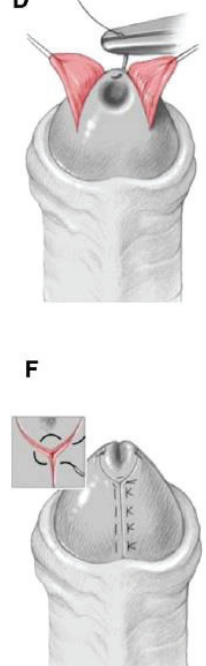
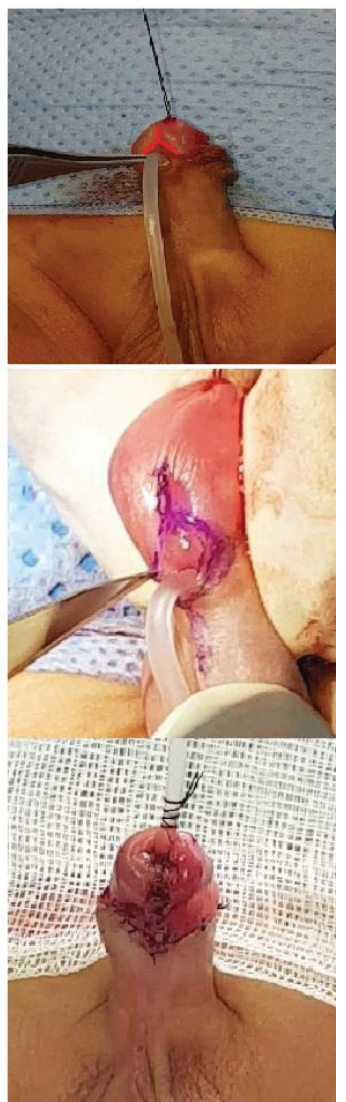

Figure 2: The different operating times of the DYG, Surgical Service A CHU Oujda.

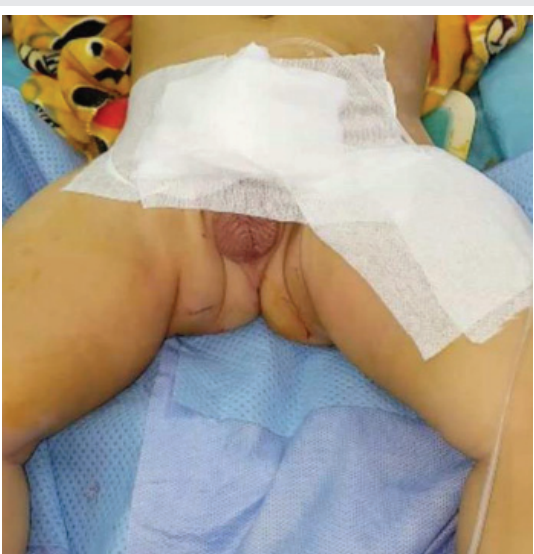

Figure 3: Photo of the fat dressing in the immediate postoperative period.

Citation: Lahfaoui M, Benhaddou H (2020) New Technique for the Treatment of Anterior Hypospadias Doubles-Y Glanuloplasty prospective Evaluation and A Systematic Review. Arch Urol Res 4(1): 028-033. DOI: https://dx.doi.org/10.17352/aur.000013 
duration of hospitalization varies between 3 and 5 days. The after-effects of the operation: were simple

The complication rate was $16 \%$ :

$>\quad 2$ cases of fistula.

$>1$ case of partial meatus stenosis.

The aesthetic and functional results were generally satisfactory according to the parents, in our series $83 \%$ of the parents were satisfied with the results.

The results were evaluated with an average decline of 20 months ( 5 to 35 months).

\section{Discussion}

Hypospad is due to insufficient virilization of the male child and is one of the sexual development anomalies $46 \mathrm{XY}$ in the new nomenclature proposed in the Chicago conference [2]. The etiology of this malformation is still unknown, although a number of studies involve genetic, hormonal or vascular disorders. In the literature; the diagnosis of hypospadias is usually made from birth during the initial physical examination of the newborn [3]. In our series; it was found that it was generally discovered by the Mother (45\%) or during circumcision (33\%), and the systematic discovery in the birth room concerned only $22 \%$ of the patients. This could be explained by the frequency of home births in our country or the absence of newborn examination by a doctor at birth; leading to a later diagnosis of the malformation. The physical examination is a crucial time; it begins with: description of the genital phenotype (Prader stages): The following elements must be specified [3].

Topography of hypospadias: in more than $80 \%$; it is anterior.

$>$ The position of the gonads: intrascrotal; single or bilateral cryptorchidism.

Associated abnormalities of the penis: A micropenis; a curvature of the penis. Indeed, the size of the penis is measured on its cavernous surface with a tape measure and its circumference or diameter at its base can be measured. Finally, the quality of erectile bodies must be assessed.

$>$ The appearance of the scrotum: pleated or not; normal or hypoplastic volume; bifid or not; and its insertion at the base of the penis or surrounding it (scrotum in scarf)

A retrospective study was conducted in 2009 [4], they evaluated the results of hypospadias surgery in 48 boys who had been diagnosed with hypospadias and had also been circumcised, they concluded that circumcision does not increase the complication rate of distal hypospadias. In our series, $22 \%$ of the operated cases were circumcised; none of them presented post-operative complications.
The combination of cryptorchidism and hypospadias is described in the literature with a percentage of $9 \%$ of cases. In the NUININGA series [5]; $9.5 \%$ of hypospads had cryptorchidism.

In the same series of NUININGA [5] the curvature of the penis is associated in $33 \%$ of cases with hypospadias. The results found in our previous series of hypospadias are consistent with those of NUININGA. The incomplete foreskin is almost associated with hypospadias, in our series $45 \%$ of cases had an incomplete foreskin.

The micropenis is less frequent in our series; in fact, it constitutes the 4th anomaly after the incomplete foreskin, curvature of the penis and cryptorchidism.

Surgical treatment aims to restore the urogenital organ's characteristics functional (urination and erection) and aesthetically acceptable [6]. Which implies:

$>$ A urethral meatus located, if possible, at the top of the glans.

$>$ A right penis in erection.

$>$ A urination with a straight stream without deflection.

An aesthetically normal penis.

The age of hospital admission in developing countries (average age 5 years) is higher than in the western part of the world due to ignorance, illiteracy, which means that patients can be operated on after the age of 4 years [7].

The American Academy of Pediatrics analysis suggests that the ideal age for genital surgery is between 6 and 12 months [8].

In our series, we operate on patients in general at the age of 4.32 years.

The DYG technique is suitable for some patients with glandular hypospadias, with mobile meatus, and in the absence of deep choreography [9].

For Ahmed T. Hadidi's DYG technique is a technique of choice for the repair of distal hypospadias, especially since the reliability of this procedure has been confirmed by the low complication rate. Hadidi conducted a study of the different factors influencing the results of this technique, where 97 cases of distal hypospadias with an average age of 12 months (between 4 and 60 months) were treated with the double $\mathrm{Y}$ glanduloplasty technique over a 6-year period. All patients received a caudal block before the operation performed under general anesthesia. The decision that the patient is suitable for the DYG technique can only be confirmed under anaesthesia after a correct evaluation of the glans and meatus and after confirmation that the meatus is mobile and can be pushed to the tip of the glans with forceps. A urethral catheter was used for 1 to 2 days depending on the degree of mobilization and the age of the child. The average duration of surgical procedures was 45 minutes. At the time of the controls, the meatus was round in a glans close to normal in 94 patients [9]. 
Initially the DYG technique was used in the first 25 patients without leaving a urethral catheter post-operatively. A compression dressing was applied for 4 to 6 hours. Children and their parents had difficulty accepting that the patient had to urinate immediately after surgery without a urinary catheter in place. So the author decided to leave the urinary catheter in place for a period of 1 to 2 days [9].

In our series the urethral catheter was used in all children for 2 to 4 days.

In the Hadidi series, five patients had a small bleeding in the dressing that stopped spontaneously within 24 hours. The average postoperative hospital stay was 2 to 3 days depending on the patient's age and the degree of postoperative edema. Two patients developed postoperative meatus stenosis 3 to 4 weeks after surgery and progressed well through dilation. A case of retraction of the meatus was noted. Probably this retraction is secondary to an initial error in the initial assessment of the degree of meatus mobility [9].

Most parents and patients reported a urine spray rather than a single flow. This occurred in more than $50 \%$ of the patients included in this study after the removal of the probe. The urine flow became unique and regular in all 94 patients after one month [9].

So according to this study, the double Y glanuloplasty technique is an excellent technique for the repair of distal hypospadias [9]. Infants recover more quickly from surgery with fewer complications than children over 3 years of age. In our department 2 patients had fistula, and one patient had meatus stenosis that required dilation.

A study [10], was conducted to compare Snodgrass' technique with Duplay's. This study was conducted by SMAIL ACIMI on 245 patients who received hypospadias repair for 8 years between April 2000 and September 2008. 113 patients benefited from the Duplay technique and 132 from the Snodgrass technique. Surgical outcomes were monitored retrospectively.

Another retrospective analysis [11], of 331 patients operated on by mathieu techniques, between May 1990 and December 2010 to monitor the results of this technique.

A retrospective evaluation of Koff's urethral translation technique [12], conducted by January 1, 1999 to January 31, 2001, about 26 cases.

We will compare the patients treated by these 4 techniques with the results of the series of Ahmed T. Hadidi [9] and our series (Table 1).

Aesthetic and functional results were generally satisfactory according to the parents; in our series $83 \%$ of parents were satisfied with the results. However, the cosmetic aspect obtained with the DYG techniques and Snodgrass was considered superior to that obtained with the Duplay ,Koff and Mathieu technique, because with DYG and Snodgrass, the meatus in all patients was in a normal position and vertically
Table 1: Comparison of complications of the different techniques.

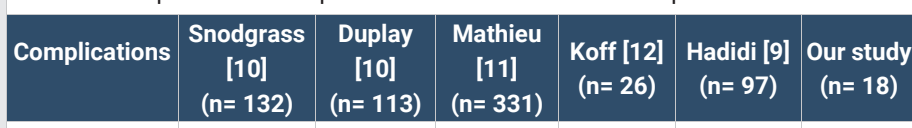

\begin{tabular}{|c|c|c|c|c|c|c|}
\hline Fistula & $4(3 \%)$ & $9(8 \%)$ & $38(11 \%)$ & $1(4 \%)$ & $0(0 \%)$ & $2(11 \%)$ \\
\hline $\begin{array}{c}\text { Stenosis of the } \\
\text { urinary meatus }\end{array}$ & $29(22 \%)$ & $8(7 \%)$ & $1(0.3 \%)$ & $5(19 \%)$ & $2(2 \%)$ & $1(5 \%)$ \\
\hline Dehiscence & $0(0 \%)$ & $0(0 \%)$ & $0(0 \%)$ & $0(0 \%)$ & $1(1 \%)$ & $0(0 \%)$ \\
\hline Diverticule & $2(1.5 \%)$ & $0(0 \%)$ & $0(0 \%)$ & $0(0 \%)$ & $0(0 \%)$ & $0(0 \%)$ \\
\hline Total & $35(23.5 \%)$ & $17(12.5 \%)$ & $39(12 \%)$ & $6(23 \%)$ & $3(3 \%)$ & $3(16 \%)$ \\
\hline
\end{tabular}

oriented. On the other hand, with the technique of Duplay, Koff and Mathieu, it was not always easy to position the meatus at the top of the glans [10]. According to the SMAIL ACIMI study [10], thanks to the median incision added to the Duplay, Snodgrass has delivered a procedure that brings the urethral meatus to the top of the glans, and thus achieves an excellent aesthetic appearance with less fistulas. However, the rate of stenosis encountered with this technique remains high.

The author concludes that when the distal hypospadias is associated with a deep urethral plate, this hypospadias should be corrected by the Duplay procedure, but when it is shallower, or even non-existent, the Snodgrass technique is the most appropriate because it gives an excellent aesthetic appearance with a low fistula rate [10].

Hadidi [9] concluded that the DYG technique is a simple technique adapted to patients with anterior hypospadias with a mobile meatus, without deep choreography. This technique allows to obtain a slit-shaped terminal meatus with a minimum of complications [9].

\section{Conclusion}

Comparison of doubleY glanduloplasty with other techniques used in anterior hypospadias shows that complications are much less frequent with DYG, with satisfactory aesthetic and functional results. Don strongly recommends the use of this technique in glandular hypospadias with a mobile meatus and without deep chordate. A prospective comparative single-blind cohort study is underway to confirm these results.

\section{References}

1. Boudaoud N, Pons M, Pillon MB, Lefebvre F, Merol MP, et al. (2016) Hypospadias.

2. Lee PA, Houk CP, Ahmed SF, Hughes IA (2006) Consensus Statemen On Management Of Intersex Disorders. J Pediatr Urol 2: 148-162. Link: https://bit.ly/2SBCb3R

3. Moscovici V, Hypospadias J, Sauramps M (2003) Montpellier: Monographie Du Collège National De Chirurgie Pédiatrique.

4. Pieretti RV, Pieretti A, Pieretti-Vanmarcke R (2009) Circumcised Hypospadias Pediatr Surg Int 25: 53-55. Link: https://bit.ly/35xd5Iw

5. Nuininga JE, DE Gier RP, Verschuren R, Feitz WF (2005) Long-Term Outcome Of Different Types Of One Stage Hyposoadias Repair. J Urol 174: 1544-1548. Link: https://bit.ly/35ymDTt 
6. Palmer JS (2012) Abnormalities Of The External Genitalia In Boys. CampbellWalsh Urol 44: 3537-3556.E4.

7. Bhat A (2007) Extended Urethral Mobilization In Incised Plate Urethroplasty For Severe Hypospadias: A Variation In Technique To Improve Chordee Correction. J Urol 178: 1031-1035. Link: https://bit.ly/2KYoyHL

8. American Academy Of Pediatrics (1996) Timing Of Elective Surgery On The Genitalia Of Male Children With Particular Reference To The Risks, Benefits, And Psychological Effects Of Surgery And Anesthesia. Pediatrics 97: 590-594. Link: https://bit.ly/2STID7F

9. Hadidi AT (2010) Double Y Glanuloplasty For Glanular Hypospadias. J Pediatr Surg 45: 655-660. Link: https://bit.ly/2WuUXe5
10. Acimi (2011) Comparative Study Of Two Techniques Used In Dista Hypospadias Repair :Tubularized Incised Plate (Snodgrass) And Tubularized Urethral Plate (Duplay). Scand J Urol Nephrol 45: 68-71. Link: https://bit.ly/2SEksZw

11. For T, Hypospadias D, Experience AY (2017) International Section. 70: 679 687

12. Paparel P, Mure PY, Garignon C, Mouriquand P (2001) Translation Uréthrale De Koff : À Propos De 26 Hypospades Présentant Une Division Distale Du Corps Spongieux. Prog Urol 11: 1327-1330. Link: https://bit.ly/2zgWs7J
Discover a bigger Impact and Visibility of your article publication with

\section{Peertechz Publications}

\section{Highlights}

* Signatory publisher of ORCID

* Signatory Publisher of DORA (San Francisco Declaration on Research Assessment)

- Articles archived in worlds' renowned service providers such as Portico, CNKI, AGRIS, TDNet, Base (Bielefeld University Library), CrossRef, Scilit, J-Gate etc.

* Journals indexed in ICMJE, SHERPA/ROMEO, Google Scholar etc.

* OAI-PMH (Open Archives Initiative Protocol for Metadata Harvesting)

* Dedicated Editorial Board for every journal

* Accurate and rapid peer-review process

* Increased citations of published articles through promotions

* Reduced timeline for article publication

Submit your articles and experience a new surge in publication services

(https://www.peertechz.com/submission).

Peertechz journals wishes everlasting success in your every endeavours.

Copyright: @ 2020 Lahfaoui M, et al. This is an open-access article distributed under the terms of the Creative Commons Attribution License, which permits unrestricted use, distribution, and reproduction in any medium, provided the original author and source are credited.

Citation: Lahfaoui M, Benhaddou H (2020) New Technique for the Treatment of Anterior Hypospadias Doubles-Y Glanuloplasty prospective Evaluation and A Systematic Review. Arch Urol Res 4(1): 028-033. DOI: https://dx.doi.org/10.17352/aur.000013 